\title{
Implementation of Modeling Instruction in a High School Chemistry Unit on Energy and States of Matter
}

\author{
Judith L. Jenkins $^{1 *}$, Elizabeth M. Howard ${ }^{2}$ \\ 'Department of Chemistry, Eastern Kentucky University, Richmond, Kentucky, 40475, United States, '2Department of Technology, Valvoline Inc., \\ Lexington, Kentucky, 40509, United States
}

*Corresponding author: judy.jenkins@eku.edu

\section{ABSTRACT}

Interest in student-centered active learning pedagogies is widespread, but discipline-specific examples of implemented instructional approaches are needed to bridge the gap between pedagogical ideas and their enactment. One of these approaches, Modeling Instruction, is an active, student-centered approach wherein students learn through construction and application of conceptual particle models to understand, interpret, and predict observable phenomena. Here, we demonstrate implementation of Modeling Instruction to teach concepts from an Energy and States of Matter unit in high school chemistry. This preliminary study allowed us to begin to understand the connections between the method, student learning, and student attitudes. Analyses of pre-test, unit exam, and final exam questions provide qualitative support of the method's efficacy. For the two objectives examined here, over $60 \%$ of students demonstrated mastery by the end of a unit taught through Modeling Instruction. Semester-long improvements in exam scores suggest that Modeling Instruction facilitates content mastery and retention more effectively than traditional instruction. Finally, anecdotal evidence, particularly insights into student mindset, shows that Modeling Instruction positively impacts the ways students think about their own learning.

KEY WORDS: chemistry; constructivism; inquiry-based/discovery learning; active learning; modeling instruction

\section{INTRODUCTION}

M odeling Instruction is a research-based pedagogy wherein students learn through construction and application of conceptual particle models to understand, interpret, and predict observable phenomena. Pioneered by Hestenes et al., Modeling Instruction was first used to teach high school physics in the United States (Hestenes, 1987). The positive impacts of the technique in physics classrooms at the high school and college levels are welldocumented (Hestenes et al., 1992; Liang et al., 2012; Malone, 2008; Wells et al., 1995). The more recent implementation of modeling instruction in high school chemistry is timely, as the next generation science standards (NGSS) articulate proficiency in science through the dimensions of disciplinary core ideas, cross-cutting concepts, and practices - placing emphasis on students doing science to learn science (Dukerich, 2015). Rather than memorizing a collection of scientific facts that seem unrelated to newer learners, students learning through Modeling Instruction employ processes similar to those used to realize scientific understanding throughout history. Students make observations and then work individually or in small groups to explain the observations, often using particle diagrams. Explanations are then shared, refined, and used to generate more broad conceptual models.

Based on the well-documented success in physics and the emerging indicators of positive impact in chemistry (Cullen, 2015; Edwards and Head, 2016; Kimberlin and
Yezierski, 2016), we hypothesize that Modeling Instruction is an effective way for students to understand and master content in high school chemistry. We also acknowledge that the implementation of emerging pedagogies is facilitated by practical examples of the approach and its impacts. Thus, in this study, we examine two learning objectives from energy and states of matter unit. Students individually answer a free-response assessment question for each objective in a pre-test, a unit exam, and a cumulative semester final exam. The evolution of students' answers from pre-test to unit exam illuminate students' thought processes as they learn - allowing the teacher to see student misconceptions and to gauge student learning progress. The answers on the cumulative semester final exam give some indication of students' longer-term retention of content knowledge. Comparison of student exam scores over the course of a semester as a function of the instructional method (traditional vs. modeling instruction) demonstrate the impacts of instructional method on student retention and course progress. Together, these results help us understand how modeling instruction impacts the students' learning processes and the efficacy of the method on content mastery and retention, providing preliminary evidence in support of the method's implementation in high school chemistry.

\section{BACKGROUND}

Well-documented and wide-ranging student misconceptions motivate educators to rethink approaches to teaching 
chemistry (Nakhleh, 1992), though the motivations for changed methodology and the approaches are relevant to many scientific disciplines. Some student misconceptions are concept-specific. For instance, chemistry learners frequently struggle to distinguish phase changes from chemical reactions, which imply that students may have a specific understanding of the states of matter while lacking unifying conceptual knowledge relevant to chemical bonding and noncovalent interactions (Jasien, 2013). More broad chemical misunderstandings are evidenced by students' difficulty relating concepts taught in different courses and even different lessons. For instance, students struggle to move between macroscopic, microscopic, and symbolic representations of chemical phenomena, which implies situation-specific interpretation without connecting the multiple ways of observing and depicting the same phenomenon (Cooper et al. 2010). As a result, teacher-centered approaches designed to explain and convey factual knowledge from teacher to student are gradually being replaced by student-centered methodologies and activities such as problem-based learning, process-oriented guided inquiry learning, peer-led team learning, think-pair-share, and jigsaw groups (Freeman et al., 2014). Modeling Instruction, the focus of this work, combines the active student-centered components of these methods with strategic concept organization designed to develop understanding not only of the concepts encountered but also of their interrelatedness (Hestenes, 1987; Wells et al., 1995); the resulting student conceptual understanding is appropriately scaffolded leading to deep, meaningful, and functional understanding of the subject matter.

\section{Modeling Instruction}

The goals of Modeling Instruction as a means of teaching and learning chemistry, as clearly articulated by Dukerich, (2015), are that students will: Construct and use scientific models to describe, to explain, to predict, and to control physical phenomena; model physical objects and processes using diagrammatic, graphical, and algebraic representations; recognize a small set of particle models as the content core of chemistry; evaluate scientific models through comparison with empirical data; and view Modeling as the procedural core of scientific knowledge (p. 1315).

This student-centered method prioritizes the development of conceptual understanding by providing evidence of concepts and their inherent interrelatedness (Cullen, 2015). As such, the goals of Modeling Instruction are enabled by two key factors the use of class time and the organization of content (American Modeling Teachers Association, 2018; Dukerich, 2015).

During class, students discover concepts - doing science to learn science. Every objective is introduced through a laboratory activity of some sort, often student-designed. Rather than the lab confirming content provided through lecture or other means, the lab is the students' first introduction to content and concepts; the lab provides the evidence that the students then work to understand, use to refine explanations, and apply to interpret new observations. Once a lab exercise is completed, students work in small groups to draw out the observed phenomena on whiteboards. Initially, these depictions may contain only a macroscopic perspective of a given phenomenon. However, in the first days of a class taught through Modeling Instruction, students learn to represent macroscopic phenomena with particles. Representative examples of drawings generated in this study are shown in Figure 1.

After the students' initial attempts to draw what they have observed in a lab activity, the teacher facilitates a class discussion, guiding students to a more thorough understanding of the content. Students are encouraged to make connections between what they observed and what happened at the particle level. Students use each other's understandings to both defend and refine their own understanding of the concept. In addition, students interpret their evidence in light of evidence collected in other labs. Once the discussion is over, students complete a post-lab analysis to show their understanding of the material that was observed in the lab. In some cases, students complete an extension worksheet that might introduce calculations or application questions to deepen their thinking. At the conclusion, a quick set of notes is generated to summarize the interpretations of the evidence. This cycle (lab, draw, discuss, refine, extend, and summarize) repeats for additional objectives, progressing through interrelated concepts.

Strategic conceptual progression is critically important in achieving the goals of Modeling Instruction. In accordance with constructivist thinking, concepts are ordered such that foundations are built, refined, and built on throughout the course. Progressively, interpretation of the evidence obtained during lab activities both depends on and challenges conclusions reached during other activities such that the interrelatedness of concepts becomes self-evident and explicitly stated. For instance, in early laboratories, students depict phenomena with particles that are neutral, uniform in size, and that do not experience any attraction nor repulsion (ex. conservation of mass). While these particles are sufficient for explaining some observations, the following labs generate observations that may not be explainable without more nuanced perspectives on particles - particles with different shapes and sizes, particles with charges, or particles with different chemical identities (ex. atomic emission). The ways in which students use new evidence to refine their models intentionally mirrors historical scientific progress, letting students experience discovery not only within a given lesson but also across the course (and beyond).

The role of the teacher when using Modeling Instruction is largely that of an experienced facilitator and a conceptual architect. The teacher enables discovery - preparing lab materials and guiding students during labs as needed and organizing the labs such that the concepts build on one another. While students work to depict their observations, the teacher may choose to ask questions that require students to deepen, clarify, and expand their explanations. The teacher serves as a 


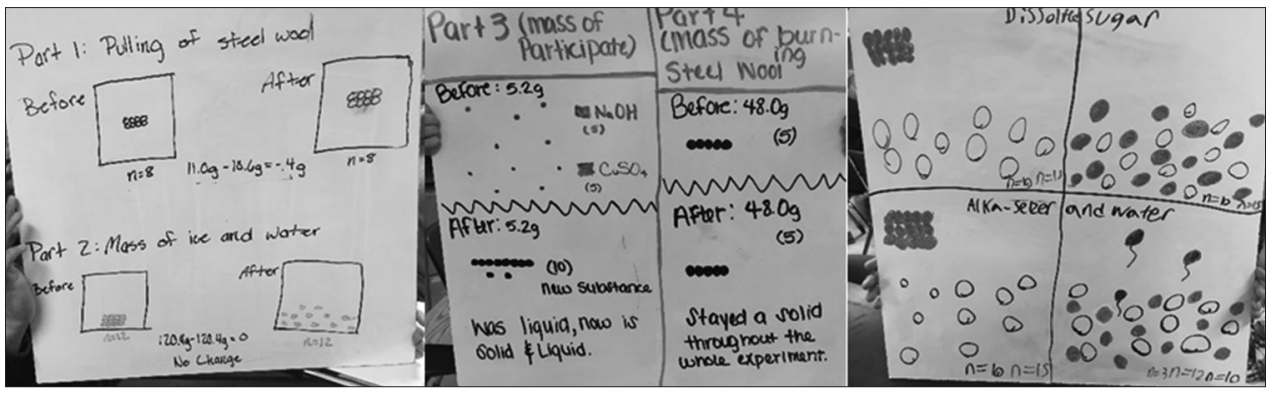

Figure 1: Whiteboard depictions generated in response to the following prompt: Draw a before and after particle picture for the following scenarios. Explain how the particle diagrams demonstrate obedience to the law of conservation of mass

moderator while students compare their depictions and refine their understandings. Importantly, student misconceptions often become very clear during the discussion, providing the teacher with opportunities to address immediately false impressions and misconstructions. Resources for teachers interested in implementing Modeling Instruction, including course materials and professional development opportunities, can be found through the American Modeling Teacher Association's website (American Modeling Teachers Association, 2018).

\section{Modeling Instructions and Education Standards}

Practical implementation of instructional approaches requires straightforward alignment with educational standards. The NGSS are now widely implemented in the United States K-12 system, so pedagogical changes must be carried out in ways that clearly facilitate the realization of these standards (National Research Council, 2012). In deviation from previous standards, NGSS outlines not only what students should know (Disciplinary Core Ideas) but also how the content is related (Crosscutting Concepts) and what students should be able to do (Science and Engineering Practices). This three-dimensional approach to science education is readily enabled by the content organization and the discovery-driven approaches in Modeling Instruction. Readers are referred to a recent article by Dukerich for additional discussion of the technique's alignment with NGSS (Dukerich, 2015).

The science practices defined by NGSS articulate what scientists do as they investigate and interpret phenomena, assuming that students engage in these practices as they learn. These practices include asking questions, developing/ using models, planning/carrying out investigations, analyzing/ interpreting data, using mathematics and computational thinking, constructing explanations, engaging in argument from evidence, and obtaining, evaluating, and communicating information (National Research Council, 2012). As described in the previous section, the goals of modeling instruction closely mirror these practices, and the use of classroom time regularly engages students in these practices.

The disciplinary core ideas and the crosscutting concepts described by NGSS are notable because they quite intentionally avoid dividing content into traditional science disciplines (chemistry, biology, physics, etc.). The crosscutting concepts, as the name implies, persist through all disciplines, including patterns, cause and effect, energy and matter, structure and function, and stability and change; similarly, the core ideas are grouped into physical sciences, life sciences, earth and space sciences, and engineering, technology, and applications of science (National Research Council, 2012). This organizational structure allows students to genuinely observe and experience the interconnectedness of the content and concepts. Simultaneously, this structure makes space for (and perhaps even necessitates) instructional approaches like Modeling Instruction, which organize content in ways that differ significantly from more traditional chemistry courses with the specific aim of thoroughly scaffolded student learning. At a more granular level, modeling instruction is well-aligned with the NGSS Disciplinary core ideas that are most naturally encountered in high school science classes. For instance, the activities described in this work correspond with the overarching NGSS Physical Science Core Idea 3 (PS3) Energy and its high school manifestation (HS PS3-2) which states that students will be able to "develop and use models to illustrate that energy at the macroscopic scale can be accounted for as a combination of energy associated with the motions of particles (objects) and energy associated with the relative position of particles (objects)" (National Research Council, 2013, p. 97).

\section{METHODOLOGY}

Description of the School, the Students, and the Classroom Madison central high school (MCHS) serves approximately 1900 students, Grades 9-12, in Richmond, Kentucky, USA. MCHS is characterized as Title 1 school, meaning that due to the large number of its students from low-income families, the school receives supplemental funding. For instance, in the academic year 2015-2016, 48\% of the student body received free or reduced-price lunch (Kentucky Department of Education, 2018b). After graduating from MCHS, 64\% of students attend college, 20\% enter the workforce, and 3\% join the military; the destinations of the remaining $13 \%$ are unknown. Of the MCHS students entering college, only $36 \%$ meet the ACT College Readiness Benchmark for science (score of 23 or higher on the ACT Science Sub-test) (Kentucky Department of Education, 2018a).

Modeling Instruction was implemented in two sections of general level chemistry (46 students total) during the academic 
year 2016-2017. This elective course is taken by juniors and seniors (students aged 15-18) who are likely to attend university, but who are not interested in pursuing a science major. Students from a previous general level chemistry course taught by the same instructor in the academic year 2014-2015 serve as a control group (30 students) and are herein referred to as the traditional cohort. For both cohorts, the course met 5 times/week for $55 \mathrm{~min}$ each class period. Portable dry-erase boards were the only non-standard classroom supply that was critically important to the implementation of Modeling Instruction. Other types of boards could be substituted if the boards were erasable, durable, relatively large, and easily moved about.

Here, the traditional method is thought of as a teacher-led classroom where content is presented and explained rather than discovered. Powerpoint is used to present the material in a non-interactive, lecture-type format as students observe, and most passively. Students then practice the presented content with a worksheet. A lab follows, so students physically see the content for themselves. While the worksheets and labs to provide students with opportunities for hands-on interactive experiences, and though students have ample opportunities for asking questions, these experiences are largely designed to support conclusions presented through lecture. Students rarely form and test hypotheses in this format; the process of doing science to learn science is largely absent.

\section{Study Details}

The authors completed all required training for human subject research, offered through Eastern Kentucky University's (EKU) online subscription to the Collaborative Institutional Training Initiative (EKU IRB, 2018). The study was approved through EKU's Institutional Review Board (IRB) in the Exempt category. MCHS students and parents were made aware of the study through the course syllabus and a verbal explanation given on the $1^{\text {st }}$ day of classes by the teacher; per EKU's IRB policies; signed consent forms are not required for exempt studies (EKU IRB, 2018). At the request of a student or parent, any student that did not want to participate in the study could be transferred into a different section of the course; none chose this option.

During the first unit of the academic year, which is not evaluated by this study but described here for context, students gained familiarity with the general process of modeling instruction. Students generated particle diagrams as models for observed phenomena with a focus on conservation of matter - learning how to represent solids, liquids, and gases as particles. These initial exercises established a common vocabulary, a classroom culture of open discussion, and the process of iterative model development and refinement. Representative questions from this first unit are shown in Figure 1. The "energy and states of matter" unit directly followed this unit and are the focus of this study.

We hypothesize that modeling instruction is an effective way for students to achieve content mastery in high school chemistry. To test this hypothesis, two unit objectives and two questions designed to assess these objectives were developed from materials provided by the American Modeling Teachers Association with permission (American Modeling Teachers Association, 2018). The objectives, assessment questions, and answers demonstrating content mastery will be discussed below.

To establish the students' baseline understanding of these concepts, students answered two assessment questions as a pre-test. Pre-tests were used solely for purposes of the study; they were not returned to students, nor did they impact student course grades. The same questions were answered on the unit exam and the semester final exam. The unit activities between the pre-test and unit exam occurred over 9 weeks split by a holiday break. Students generated their own study guides organized around the following categories: Diffusion of gases and liquids, kinetic molecular theory, thermal expansion, pressure, air/barometric pressure, and PVTn before the unit exam. In the 1 week between the unit exam and the semester final exam, students reviewed material from both units facilitated by a provided study guide.

Student responses to the assessment questions on the pretest, unit exam, and semester final exam were categorized as a proficient, apprentice, or novice by each coauthor independently; the few differences were then discussed and easily reconciled. Proficient responses correctly answered and explained all portions of a given question, demonstrating content mastery. Apprentice responses were partially correct but may contain some misconceptions, factual inaccuracies, and/or logical inconsistencies. Novice responses included broad misconceptions, completely factually inaccurate statements, and blank responses; no portion of the answer demonstrated conceptual understanding.

To examine student performance over the course of the semester as a function of instructional method, we compared exam scores on the first unit exam (given in September) to the cumulative semester final exam (given in December) scores for both the traditional cohort and the cohort learning through Modeling Instruction. While some students' exam grades remained the same, other students' grades increased or decreased by one or more letter grade. In this work, p-values were computed to determine the statistical significance of exam score changes (or lack thereof) over the course of a semester as a function of instructional method. The null hypothesis was that changes in exam scores (if any) were independent of the instructional method and was rejected using $p<0.01$ as a measure of significant difference.

We recognize the limits of this study; the small sample size tempers the strength of the conclusions, and the relatively short time period over which student responses were analyzed makes it difficult to quantify retention. Nevertheless, this study provides an example of implemented active learning pedagogy as well as a manageable and meaningful strategy for understanding the impacts of modeling instruction on student 
learning, contributing to the broad ongoing investigation of instructional methodologies (Freeman et al., 2014; Frey et al., 2017).

\section{RESULTS AND DISCUSSION}

Objective 1 - Relate Kinetic Energy, Particle Motion, and Thermal Expansion

To achieve this objective, students were challenged to depict observed phenomena at the molecular level using particle diagrams. For instance, in an interactive demonstration, two Erlenmeyer flasks were placed on a hot plate - one contained water and the other contained isopropyl alcohol. One-hole stoppers fitted with glass tubing ( $\sim 1 / 4$ inch diameter) were prepared ahead of time and used to stopper each flask loosely. The tubes were adjusted such that (i) the bottom of the glass tube was immersed and the top of the glass tube protruded several centimeters above the stopper and (ii) at room temperature, the height of the water in the tube equaled the height of the isopropyl alcohol in the other tube. Then, the flasks were heated. Each time the temperature increased $5^{\circ} \mathrm{C}$, students marked the liquid levels on the tubes; the experiment was concluded when the temperature reached $60^{\circ} \mathrm{C}$. Students then worked in groups of 3-4 to draw particle pictures of the water and the isopropyl alcohol before and after heating, resulting in drawings similar to the depictions in Figure 2a. After $10 \mathrm{~min}$, the whole class formed a circle and discussed the whiteboard particle drawings.

During the discussion of the particle drawings, the teacher challenged the students to use their particle diagrams to explain what was happening when the liquids rose in the tubes. By the end of the class period, students collectively developed this explanation for what was observed - the space occupied by the liquid increased when the liquid was heated (energy added), causing the particles to move over a larger area as evidenced by the liquid moving up the tube. Therefore, adding energy must have an effect on the motion of the particles and their interactions with one another. Specifically, the particles move more quickly, collide more frequently, collide with more energy, etc., such that the space between particles increases to cause the observed expansion of the liquid. The teacher labeled the phenomenon as thermal expansion. After this discussion, students individually completed a post-lab analysis, applying information from the activity to answer the following questions: (1) How does the expansion of water differ from that of alcohol as temperature changes? and (2) draw the particle diagrams for water at $25^{\circ} \mathrm{C}$, water at $50^{\circ} \mathrm{C}$, and alcohol at $50^{\circ} \mathrm{C}$. These analyses were graded and returned to the students with specific feedback, providing an opportunity for a reconciliation of misconceptions.

The assessment question used to probe mastery of objective one was: A thermometer is placed in a beaker of warm water. Explain what is going on at the particle level as the reading on the thermometer rises from $25^{\circ} \mathrm{C}$ to $40^{\circ} \mathrm{C}$. Students demonstrating mastery were able to relate changes in energy to changes in particle motions and/or interactions. Figure 3 contains a representative student progression from pre-test (Figure 3a) to the unit exam (Figure 3b). Answers similar to that in Figure $3 \mathrm{a}$ were scored as an apprentice because these answers contain some correct analyses but are incomplete. Apprentice-level responses correctly explained energy changes OR particle motion/interaction (more collisions, more space between particles, etc.). Answers similar to that in Figure 3b were scored as proficient and indicated conceptual mastery. It is important to note that students at this stage of the course view all molecules as neutral, spherical particles. As such, explanations were not expected to include discussion of intermolecular forces (Ex. hydrogen bonding) and their impact on the observed phenomena.

Only three students demonstrated mastery of objective 1 on the pre-test; 24 of 46 students gave some version of the partially correct but incomplete response, "the particles move faster as

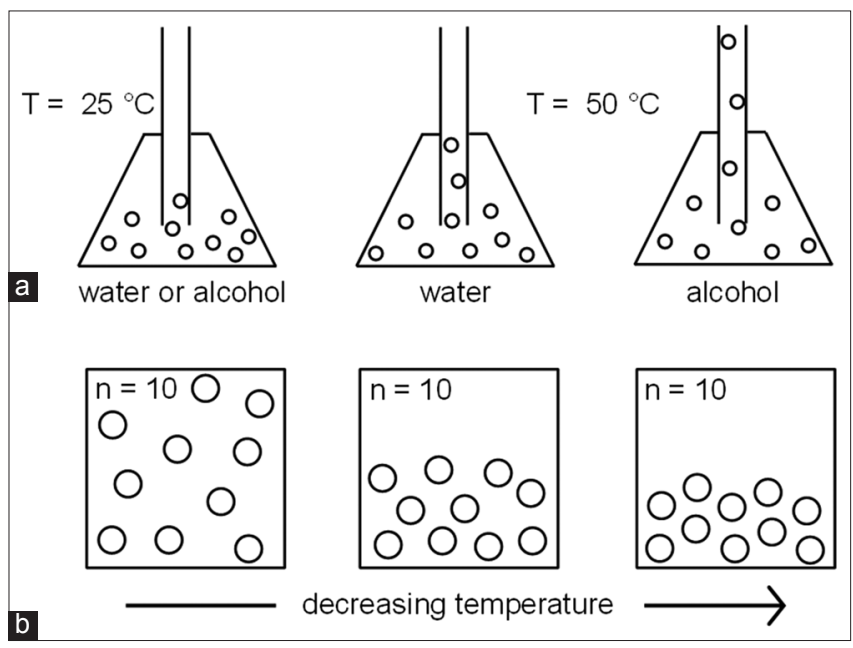

Figure 2: ( $a$ and b) Depictions of student-generated particle diagrams used to explain the particle-level phenomena occurring during the interactive demonstration (a) and to predict the impact of temperature on particle behavior (b)

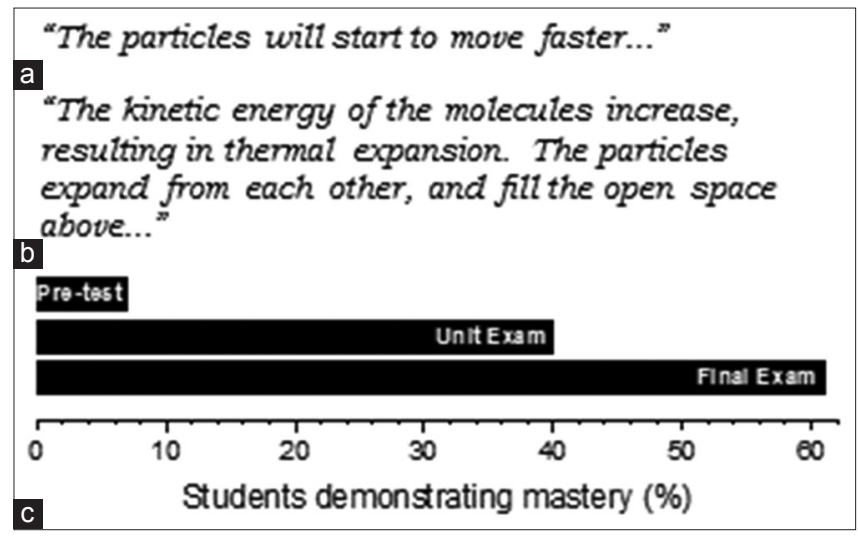

Figure 3: (a-b) Representative student response scored apprentice (a) and proficient (b) for objective 1; the percentage of students demonstrating content mastery throughout the semester (c) 
the temperature increases." Two key conceptual disconnects were observed in the pre-test responses. First, 11 students gave responses such as "the particles warm up," revealing that some of the students were assigning the observable behavior of the liquid to each individual particle in the liquid, as if one could place a thermometer on a single particle and measure the same temperature change observed for the liquid. Second, four students suggested that the particles underwent a chemical reaction to yield an increase in temperature, reminiscent of the well-documented difficulties students have in distinguishing between phase changes and chemical reactions (Jasien, 2013). While these misconceptions are common, true concept mastery requires that these ideas be revealed and the scaffolding is corrected. Together, these pre-test responses illustrate a key strength of modeling instruction - rapid identification of student misconceptions enabling near-immediate feedback and informing future instruction.

For objective one, $72 \%$ (32 of 46 students) displayed some improvement from their pre-test responses. Mastery was demonstrated by $40 \%$ (17 students) and $61 \%$ (28 students) on the unit exam and final exam, respectively (Figure 3c). Importantly, after the learning activities, no students implicated chemical reactions to explain the particle behavior, and those that did say particles warmed expanded their answers to include some combination of energy, particle motion, or particle interaction.

\section{Objective 2 - Explain the Relationship between Temperature and Particle Motion}

This objective extends objective one to higher-order thinking skills and processes - challenging students to move beyond a specific system and develop more broad constructs that can be used to describe, predict, and explain a wide range of observed phenomena. Following the whole-class analysis of the previously described interactive demonstration, an extension activity gave students the opportunity to apply the concept of thermal expansion to situations beyond thermometers. Asked to explain what happens to particle motion when the temperature decreases, students worked in groups to write/ draw answers on whiteboards, resulting in depictions similar to those found in Figure 2b. Then, each group shared their answer with the class while other class members could agree or disagree before a final depiction was suggested and agreed on. Through this scaffolding process, students used their observations of cause and effect (fluid rising in a tube when heated) and their corresponding explanation (thermal expansion) to reach a more generally applicable conceptual understanding. This student-centered knowledge construction showcases the strengths of modeling instruction, which provided students the vocabulary and skills to first represent observed phenomena at the particle level and then manipulate the particle representations to predict/explain what would be observed under different conditions.

The assessment question for objective two was: If the temperature in the box decreased, what would happen to the motion of the particles? Explain your answer. A square box with five spherical particles appeared next to the question. Although 33 students correctly predicted what would happen on the pre-test, only five students displayed mastery by supporting their predictions with proper explanations. A representative example of the most common prediction offered by students is shown in Figure $4 a-$ the particles will slow down. This response, as well as those shown in Figures $4 b$ and $4 c$ were scored apprentice if given without explanation. An explanation restating the question (because the temperature goes down) was not considered sufficient. Instead, complete answers resemble those in Figure 4d. At the mastery level, students move beyond restating the question to various ways of demonstrating full understanding - compare/contrast increases and decreases in temperature, note that there is a direct relationship between temperature and motion or temperature and energy, etc. (Taber and Watts, 2000).

As with the previous question, this question elicited student misconceptions. The most common was a version of "the pressure of the particles decreases," an example of composite behavior assigned to an individual particle. This articulated misconception provides opportunities for feedback and reconciliation throughout the unit. 33 students showed improvement from the pre-test to the unit exam or final exam, and 30 students $(65 \%)$ showed mastery on the unit exam and final exam (Figure 4c). The higher-level thinking skills required to master this objective are evidenced by the multiple correct answers (Figure 4) provided by students in identifying what will happen to the particles as temperature decreases (Taber and Watts, 2000). Ultimately, questions like these provide an opportunity for educators to help students move beyond their developing chemical intuition (Ex. I know what would happen, but I can't quite articulate why I know that) to a more confident, deeper understanding of the content where broad constructs are used to explain various specific situations.

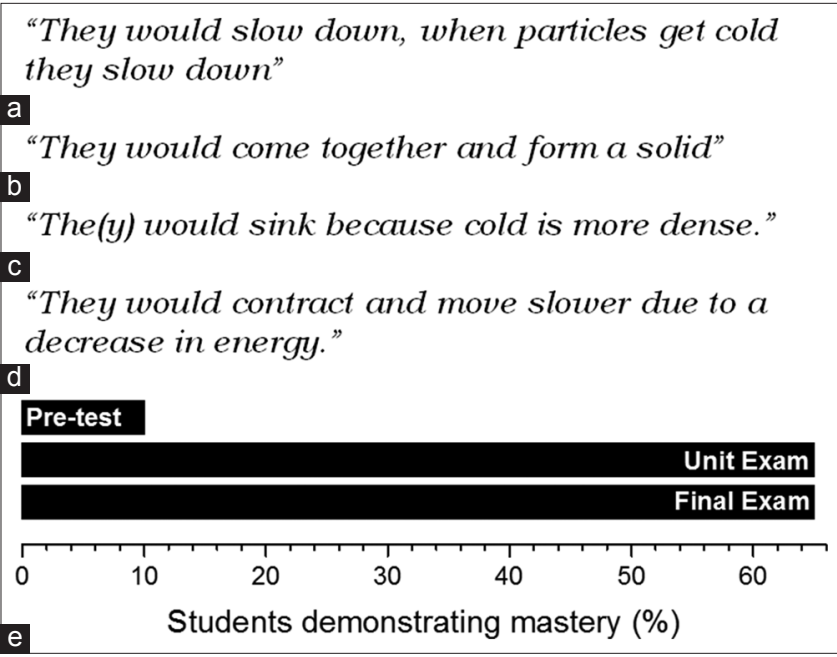

Figure 4: (a-e) Representative student responses scored apprentice (a-c) and proficient (d) for objective two; the percentage of students demonstrating content mastery throughout the semester (e) 


\section{General Comments}

Although there is a general increase in mastery from pre-test to the final exam, the extent of mastery varies by objective. We suggest that differences in the extent of mastery reflect differences in the scope of the objectives themselves. Objective two requires higher-order thinking skills, but the scope of the content assessed in this objective is narrower than the scope of objective one. Nevertheless, the magnitudes of student improvement and concept mastery support the key hypothesis of this work - modeling instruction's positive impact on student learning in high school chemistry.

To evaluate students' thought processes more fully, future implementation would be strengthened by the use of a concept inventory. With the help of a concept inventory, multiple questions could be used to assess a single objective, thereby reducing the impact of a student remembering a correct answer without actually understanding the concepts assessed. The efficacy of this strategy has been documented by others using modeling instruction (Dukerich, 2015; Talanquer, 2017).

\section{Cohort Comparisons}

It is instructive to consider the impacts of modeling instruction on students' learning over the course of a semester. To do so, we compared exam scores on the first unit exam (given in September) to the cumulative semester final exam (given in December) scores for both the traditional cohort from the academic year 2014 to 2015 and the cohort learning through Modeling Instruction; Figure 5. The same instructor taught both cohorts, but the order in which the content was taught differed. As such, differences in exam scores reflect differences in students' retention of content knowledge and learning generally rather than differences in the efficacies of the methodologies for specific content. Scores differing by a letter grade indicate student growth in mastery and retention (improvement, $\mathrm{x}=+1,+2$ ) or lack of growth (regression, $\mathrm{x}=-1,-2,-3)$; scores of the same letter grade on the 2 exams $(\mathrm{x}=0)$ indicate that the student's level of performance was maintained over the course of the semester. At a more granular level, change as a function of a student's unit exam score is indicated by the patterns in Figure 5 .

Student performance over the course of the semester differs as a function of the instructional method; $p$-values were computed to determine the statistical significance of these differences. The null hypothesis (student performance is independent of the instructional method) was easily rejected in all cases using $p<0.01$ as a measure of significant difference $(p<0.001$ for improvement, $\mathrm{p}<0.0005$ for maintenance, and $\mathrm{p}<0.0005$ for regression). Maintaining and improving of exam grades indicate sustained content mastery and enhanced content retention. Most strikingly, 37 of the 46 students (80\%) in the modeling instruction cohort either maintained or improved their exam grades, while only five of the 30 students $(17 \%)$ in the traditional cohort maintained or improved their exam grades. Somewhat surprisingly, those earning an A on the unit exam experienced the most regression amongst the traditional cohort students. We tentatively suggest that the exam grades may also imply differences in student motivation and persistence as a function of the instructional method; the minimal regression experienced by the Modeling Instruction cohort suggests that the technique encourages students to remain engaged with the content in meaningful ways throughout the semester. This is consistent with similar studies in physics (Brewe et al., 2009), and this is particularly important in general chemistry courses targeting students that are not likely to pursue science majors in college and therefore may begin the course with less interest in the subject.

Informal conversations with students qualitatively demonstrate modeling instruction's positive impact on students' experiences. In general, students reported enjoying the active, hands-on classroom environment, and in particular, students liked that it is okay to be wrong. Rather than thinking there is only one correct answer, students felt they learned to think like a scientist - designing labs, asking questions, discussing data, and drawing conclusions. Students expressed that use of their own interpretations of data was both exciting and empowering, helping them remember content more easily; they

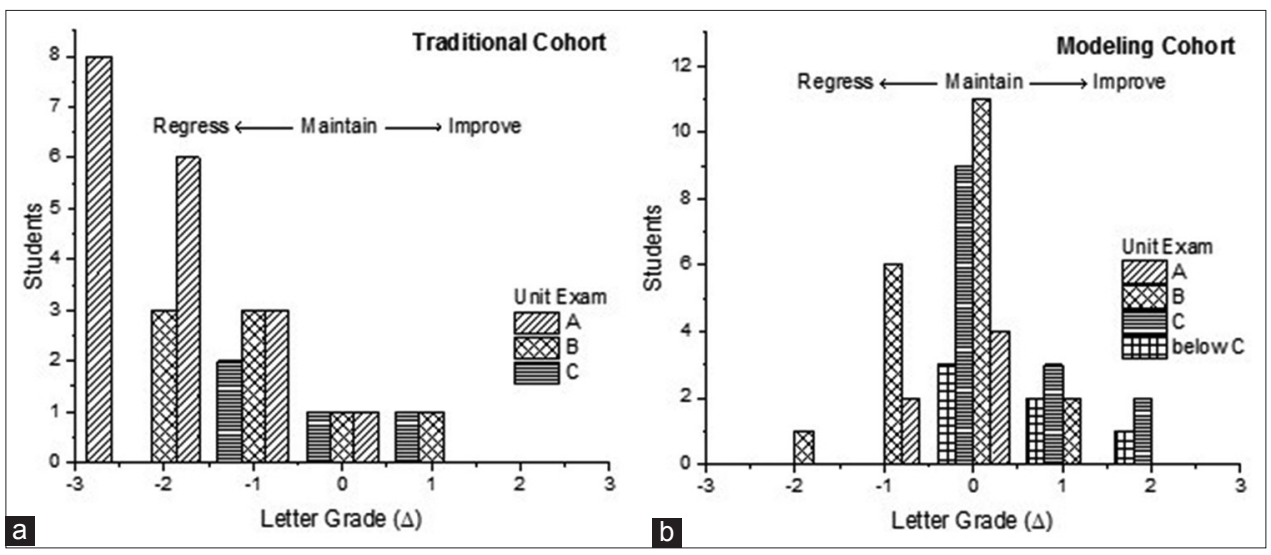

Figure 5: $(a$ and b) Exam scores from the unit exam given in September and the cumulative semester final exam given in December (represented as a change in letter grade) for the traditional cohort of 30 students (a) and the modeling instruction cohort of 46 students (b) 
used their ideas and blended them with ideas of the peers to reach a collective understanding of a concept. They also felt their scientific writing improved. Due to their active roles in performing the labs and interpreting the results, students were better able to write experimental procedures, create data tables, and graphs from collected data, and then write a conclusion that discussed what they learned, why it happened, and what they would like to do next. Although unsolicited and anecdotal, these positive student comments motivate future systematic studies of modeling instruction's impacts on both content mastery and students' mindsets.

\section{CONCLUSIONS}

Several outcomes of this study support the further refinement, implementation, and assessment of the modeling instruction's efficacy. Over $60 \%$ of students demonstrated mastery of the two objectives assessed here, which range from lower-order thinking skills (know and understand) to higher-order skills (explain/predict, develop guiding principles, and expression of concepts with multiple models). In addition, our data demonstrate some of the ways Modeling Instruction informs teaching practices by giving students the tools and vocabulary to articulate conceptual misconceptions. Semester-long trends in exam scores suggest that Modeling Instruction facilitates content mastery and retention more effectively than traditional instruction. Finally, anecdotal evidence, particularly insights into student mindset, shows that modeling instruction impacts the ways students think about their own learning. Students learn that is okay to fail and that they can construct answers from data - two critically important mindsets for life-long learners.

\section{REFERENCES}

American Modeling Teachers Association. (2018). Synopsis of Modeling Instruction. Available from: https://www.modelinginstruction.org. [Last accessed on 2019 Feb 01].

Brewe, E., Kramer, L., \& O'Brien, G. (2009). Modeling instruction: Positive attitudinal shifts in introductory physics measured with CLASS. Physical Review Special Topics Physics Education Research, 5(1), 013102-013016.

Cooper, M.M., Grove, N., Underwood, S.M., \& Klymkowsky, M.W. (2010). Lost in lewis structures: An investigation of student difficulties in developing representational competence. Journal of Chemical Education, 87(8), 869-874.

Cullen, D.M. (2015). Modeling instruction: A learning progression that makes high school chemistry more coherent to students. Journal of Chemical Education, 92(8), 1269-1272.

Dukerich, L. (2015). Applying modeling instruction to high school chemistry to improve students' conceptual understanding. Journal of Chemical Education, 92(8), 1315-1319.

Edwards, A.D., \& Head, M. (2016). Introducing a culture of modeling to enhance conceptual understanding in high school chemistry courses. Journal of Chemical Education, 93(8), 1377-1382.

Eastern Kentuky University Institutional Review Board (EKU IRB). (2018). Institutional Review Board. Available from: http://www. sponsoredprograms.eku.edu/institutional-review-board. [Last accessed on 2019 Feb 01].

Freeman, S., Eddy, S.L., McDonough, M., Smith, M.K., Okoroafor, N., Jordt, H., \& Wenderoth, M.P. (2014). Active learning increases student performance in science, engineering, and mathematics. Proceedings of the National Academy of Sciences of the United States of America, 111(23), 8410-8415.

Frey, R.F., Cahill, M.J., \& McDaniel, M.A. (2017). Students' conceptbuilding approaches: A novel predictor of success in chemistry courses. Journal of Chemical Education, 94(9), 1185-1194.

Hestenes, D. (1987). Toward a modeling theory of physics instruction. American Journal of Physics, 55(5), 440-454

Hestenes, D., Wells, M., \& Swackhamer, G. (1992). Force concept inventory. The Physics Teacher, 30(3), 141-158.

Jasien, P.G. (2013). Roles of terminology, experience, and energy concepts in student conceptions of freezing and boiling. Journal of Chemical Education, 90(12), 1609-1615.

Kentucky Department of Education. (2018a). School Report Card. Available from: http://www.applications.education.ky.gov/SRC/Default.aspx. [Last accessed on 2019 Feb 01].

Kentucky Department of Education. (2018b). Title I, Part A-Improving Academic Achievement of the Disadvantaged. Available from: https:// www.education.ky.gov/federal/progs/tia/Pages/default.aspx. [Last accesed on 2019 Feb 01]

Kimberlin, S., \& Yezierski, E. (2016). Effectiveness of inquiry-based lessons using particulate level models to develop high school students' understanding of conceptual stoichiometry. Journal of Chemical Education, 93(6), 1002-1009.

Liang, L.L., Fulmer, G.W., Majerich, D.M., Clevenstine, R., \& Howanski, R. (2012). The effects of a model-based physics curriculum program with a physics first approach: A causal-comparative study. Journal of Science Education and Technology, 21(1), 114-124.

Malone, K.L. (2008). Correlations among knowledge structures, force concept inventory, and problem-solving behaviors. Physical Review Special Topics Physics Education Research, 4(2), 020107.

Nakhleh, M.B. (1992). Why some students don't learn chemistry: Chemical misconceptions. Journal of Chemical Education, 69(3), 191.

National Research Council. (2012). A Framework for K-12 Science Education: Practices, Crosscutting Concepts, and Core Ideas. Washington, DC: The National Academies Press.

National Research Council. (2013). Next Generation Science Standards: For States, by States. Washington, DC: The National Academies Press.

Taber, K.S., \& Watts, M. (2000). Learners' explanations for chemical phenomena. Chemistry Education Research and Practice, 1(3), 329-353.

Talanquer, V. (2017). Concept inventories: Predicting the wrong answer may boost performance. Journal of Chemical Education, 94(12), 1805-1810.

Wells, M., Hestenes, D., \& Swackhamer, G. (1995). A modeling method for high school physics instruction. American Journal of Physics, 63(7), 606-619. 